\title{
Origin and switch of different colors: Thermo-isomerism and crystal structure of (1E,2E)-bis[1-(4-nitrophenyl)ethylidene] hydrazine
}

\author{
SAID TIGHADOUINI ${ }^{\mathrm{a}}$, SMAAIL RADI $^{\mathrm{a}, *}$, LOIC TOUPET $^{\mathrm{b}}$, MUHAMMAD SIRAJUDDIN $^{\mathrm{c}, *}$, \\ TAIBI BEN HADDA ${ }^{\mathrm{d}, *}$, MEHMET AKKURT $^{\mathrm{e}}$, ISMAIL WARAD ${ }^{\mathrm{f}}$, YAHIA N MABKHOT ${ }^{\mathrm{g}}$ and \\ SAQIB ALI ${ }^{\mathrm{h}}$ \\ ${ }^{a}$ LCAE, Département de Chimie, Faculté des Sciences, Université Mohammed Premier, \\ Oujda 60000, Morocco \\ b Institut de Physique de Rennes, UMR 625, Université de Rennes 1, Campus de Beaulieu Bat. 11 A, \\ 263 av. Général Leclerc, 35042 Rennes Cedex, France \\ ${ }^{\mathrm{c}}$ Department of Chemistry, University of Science \& Technology, Bannu, Pakistan \\ ${ }^{\mathrm{d}}$ Laboratoire de Chimie des Matériaux, Faculté des Sciences, Université Mohammed Premier, \\ Oujda 60000, Morocco \\ e Department of Physics, Faculty of Sciences, Erciyes University, 38039 Kayseri, Turkey \\ ${ }^{\mathrm{f}}$ Department of Chemistry, An-Najah National University, Nablus, Palestinian Territories \\ gDepartment of Chemistry, College of Science, King Saud University, P.O. Box 2455, Riyadh 1451, \\ Saudi Arabia \\ hDepartment of Chemistry, Quaid-i-Azam University, Islamabad, 45320, Pakistan \\ e-mail: radi_smaail@yahoo.fr;m.siraj09@yahoo.com; taibi.ben.hadda@gmail.com
}

MS received 9 February 2015; revised 12 August 2015; accepted 22 September 2015

\begin{abstract}
A new symmetric branched 4-nitrophenyl hydrazine compound has been prepared in one-step procedure by direct condensation of aromatic ketone with hydrazine in $\mathrm{MeOH}$. The synthesized compound, red isomer, was characterized by IR, ${ }^{1} \mathrm{H}$ and ${ }^{13} \mathrm{C}$ NMR spectroscopy, Elemental analyses, Mass spectrometry and $\mathrm{X}$-ray crystallography. Refluxing in $\mathrm{MeOH}$ solution led to thermo-isomerism offering a white isomer product that was characterized by X-ray crystallography. The red isomer crystallizes in the orthorhombic system having space group $P b c n$, with $\mathrm{a}=12.7612(4), \mathrm{b}=11.5197(3), \mathrm{c}=20.1586(7) \AA \mathrm{A}, \mathrm{V}=2963.42(16) \AA^{3}, \mathrm{Z}=8$ while the white isomer crystallizes in the triclinic system having space group $P^{-} 1$, with $\mathrm{a}=7.8007(4), 8.5966(7)$, 12.224 (1) $\AA, \alpha=71.133(7), \beta=81.281(5), \gamma=74.895(5)^{\circ}, \mathrm{V}=746.86(9) \AA^{3}, \mathrm{Z}=2$. Molecules of both compounds are twisted at N2-N3 bond with the C7-N2-N3-C9 torsion angle of 155.23(12) and -113.36(18) ${ }^{\circ}$, respectively. The crystal structures of both compounds are stabilized by weak intramolecular $\mathrm{C}-\mathrm{H}$. ... N contacts and intermolecular C-H. .O hydrogen bonding interactions. In addition, $\pi-\pi$ stacking interactions are observed between the same aromatic rings of molecules.
\end{abstract}

Keywords. Hydrazine derivative; crystal structure; thermo-isomerism; color switching.

\section{Introduction}

$\pi$-conjugated fluorescent compounds with $\mathrm{C}=\mathrm{N}-\mathrm{N}=\mathrm{C}$ moiety can be useful models for fluorescent electronic and bio-materials. ${ }^{1-17} \mathrm{~A}$ list of known $\pi$-conjugated compounds is given in Supplementary Information (figure S1). The concept of a fluorescent material is fundamentally based on intramolecular charge transfer that occurs in its simplest form in $\pi$-conjugated hydrazone systems. Hydrazones have been intensively investigated mostly because of their potential applications ${ }^{1-17}$ as antimicrobial agents and as fluorescent chemosensors

*For correspondence for metal ions. The title compound was synthesized to study antibacterial activity and fluorescence properties in order to get more detail on the structure-activity relationship by comparison with other closely related compounds.

In search of new bioactive $\pi$-conjugated fluorescent compounds to study the difference between fluorescent and normal bioactive agents, we have considered the simple case of compound (1). Cooperation between terminal substituents of phenyl groups played a key role in the trans-cis isomerism even though fluorescent compounds are used in these systems. It would then be anticipated that the two thermo isomers could be reorganized and brought selectively in close proximity such as those in nature. 


\section{Experimental}

\subsection{Materials and measurements}

All solvents and other chemicals, obtained from usual commercial sources, were of analytical grade and used without further purification. The proton NMR spectra were obtained with a Bruker AC 300 spectrometer. Elemental analyses were performed by Microanalysis Central Service (CNRS). Molecular weights were determined on a JEOL JMS DX-300 Mass Spectrometer.

\section{$2.2 X$-ray structure determination of $(\mathbf{1} \boldsymbol{a})$ and $(\mathbf{1} \boldsymbol{b})$}

Suitable single crystal of hydrazine derivative $\mathrm{C}_{16} \mathrm{H}_{14}$ $\mathrm{N}_{4} \mathrm{O}_{4}$ was obtained by recrystallization from methanol. The crystal was mounted on a glass fiber. For compounds 1a and 1b (see below), all measurements were made in the $\omega$-scan technique on a CCD Sapphire 3 Xcalibur diffractomer with graphite monochromatized $\mathrm{MoK} \alpha$ radiation at low temperature [130(2) K]. Absorption corrections were not applied. $\mathrm{H}$ atoms were geometrically located in calculated positions and treated as riding on their parent atoms, with $\mathrm{C}-\mathrm{H}=0.95$ and $0.98 \AA$, and with $\mathrm{U}_{\text {iso }}(\mathrm{H})=1.2 \mathrm{U}_{\mathrm{eq}}(\mathrm{C})$ for aromatic $\mathrm{H}$ atoms and $\mathrm{U}_{\text {iso }}(\mathrm{H})=1.5 \mathrm{U}_{\text {eq }}(\mathrm{C})$ for methyl $\mathrm{H}$ atoms.

Crystal data collection: CrysAlis CCD. ${ }^{18}$ Cell refinement: CrysAlis RED. ${ }^{18}$ Data reduction: CrysAlis RED. ${ }^{18}$ Program(s) used to solve structure: SIR97. ${ }^{19}$ Program(s) used to refine structure: SHELXL97. ${ }^{20}$ Molecular graphics: ORTEP-3 for Windows. ${ }^{21}$ Software used to prepare material for publication: WinGX. ${ }^{22}$

\section{3 (1E,2E)-bis[1-(4-nitrophenyl)ethylidene]hydrazine}

1-(4-nitrophenyl)ethanone $(5.5 \mathrm{~g}, 31.24 \mathrm{mmol})$ was dissolved in ethanol $(50 \mathrm{~mL})$ and 0.5 equivalent of hydrazine $(0.5 \mathrm{~g}, 15.63 \mathrm{mmol})$ was added. The mixture was under continuous stirring at room temperature for 3 days using two drops of catalyst (acetic acid). The formed product was filtered and washed with ethanol. The final purification was achieved by recrystallization in hot methanol solution giving two types of crystals: 1a (red isomer-1) and $\mathbf{1 b}$ (white Isomer-2) which were separated manually and characterized by X-ray crystallography.

2.3a 1a (Red Isomer-1): Yield 82.13\%. $\mathrm{Rf}=0.7$ (silica/ $\left.\mathrm{CH}_{2} \mathrm{Cl}_{2}\right)$. IR: $v(\mathrm{C}=\mathrm{N}$, imine $)=1623 \mathrm{~cm}^{-1} \cdot{ }^{1} \mathrm{H}$ NMR (300 MHz, DMSO) $\delta$ ppm: 8.29 (d, 4H, aromatic, $\left.\mathrm{C}_{3}-\mathrm{H}, \mathrm{C}_{5}-\mathrm{H}\right) ; 8.15\left(\mathrm{~d}, 4 \mathrm{H}\right.$, aromatic, $\left.\mathrm{C}_{2}-\mathrm{H}, \mathrm{C}_{6}-\mathrm{H}\right)$; 2.30 (s, 6H, imine, $\left.\mathrm{CH}_{3}\right) \cdot{ }^{13} \mathrm{C} \mathrm{NMR}(75 \mathrm{MHz}, \mathrm{DMSO})$ $\delta$ ppm: 156.5 (2C, aromatic, $\mathrm{C}_{1}$ ); 148.6 (2C, aromatic, $\left.\mathrm{C}_{4}\right), 143.9(2 \mathrm{C}$, imine, $\underline{\mathrm{C}}=\mathrm{N}) ; 128.3$ (4C, aromatic, $\mathrm{C}_{2}$, $\mathrm{C}_{6}$ ); 124.1 (4C, aromatic, $\mathrm{C}_{3}, \mathrm{C}_{5}$ ); 15.5 (2C, aliphatic, $\left.\underline{\mathrm{CH}}_{3}-\mathrm{C}=\mathrm{N}\right) . \mathrm{m} / \mathrm{z}\left(\mathrm{M}^{+}\right): 327.15$.

$2.3 \mathrm{~b} \quad \mathbf{I b}$ (White Isomer-2): Yield $10 \% . \mathrm{Rf}=0.7$ (silica/ $\left.\mathrm{CH}_{2} \mathrm{Cl}_{2}\right)$. IR: $v(\mathrm{C}=\mathrm{N}$, imine $)=1623 \mathrm{~cm}^{-1} \cdot{ }^{1} \mathrm{H}$ NMR (300 MHz, DMSO) $\delta$ ppm: 8.29 (d, 4H, aromatic, $\left.\mathrm{C}_{3}-\mathrm{H}, \mathrm{C}_{5}-\mathrm{H}\right) ; 8.15\left(\mathrm{~d}, 4 \mathrm{H}\right.$, aromatic, $\left.\mathrm{C}_{2}-\mathrm{H}, \mathrm{C}_{6}-\mathrm{H}\right) ; 2.30$ (s, 6H, imine, $\left.\mathrm{CH}_{3}\right) .{ }^{13} \mathrm{C}$ NMR (75 MHz, DMSO) $\delta$ ppm: $156.5\left(2 \mathrm{C}\right.$, aromatic, $\left.\mathrm{C}_{1}\right) ; 148.6\left(2 \mathrm{C}\right.$, aromatic, $\left.\mathrm{C}_{4}\right)$, $143.9(2 \mathrm{C}$, imine, $\mathrm{C}=\mathrm{N}) ; 128.3\left(4 \mathrm{C}\right.$, aromatic, $\mathrm{C}_{2}$, $\mathrm{C}_{6}$ ); 124.1 (4C, aromatic, $\mathrm{C}_{3}, \mathrm{C}_{5}$ ); 15.5 (2C, aliphatic, $\left.\mathrm{CH}_{3}-\mathrm{C}=\mathrm{N}\right) . \mathrm{m} / \mathrm{z}\left(\mathrm{M}^{+}\right): 327.15$.

\section{Results and Discussion}

\subsection{Chemistry}

Our strategy was to develop a simple and acceptable procedure, in one step, to prepare the desired colored compound (1). The result of our investigation is given below (scheme 1).

The title compound was also synthesized by mixing a solution (1:2 molar ratio) of hydrazine hydrate $(0.20 \mathrm{~mL}, 4 \mathrm{mmol})$ and 4-nitroacetophenone $(1.42 \mathrm{~g}$, $8 \mathrm{mmol})$ in ethanol $(50 \mathrm{~mL})$. The resulting solution was

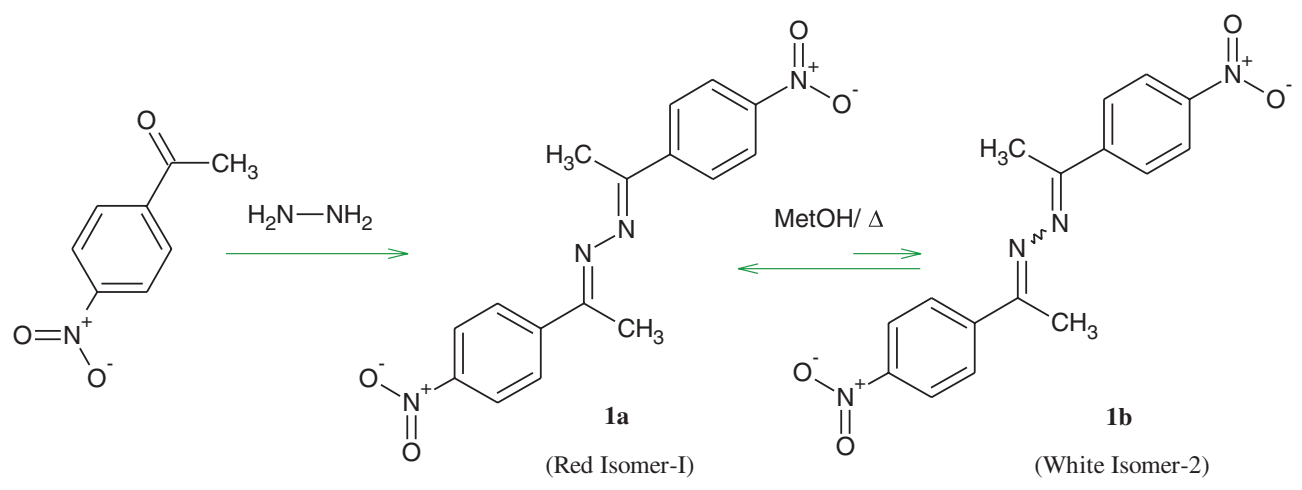

Scheme 1. Synthesis of (1E,2E)-bis[1-(4-nitrophenyl)ethylidene]hydrazine compound. 
refluxed for $4 \mathrm{~h}$ yielding a mixture of a red crystalline solid (1a) and a white crystalline solid (1b). The resultant mixture was filtered off and washed with methanol. Red and white block-shaped single crystals of the title compound suitable for X-ray structure determination were obtained by recrystalization from $\mathrm{MeOH}$ by slow evaporation of the solvent at room temperature over three days.

\subsection{Crystal structures of $\mathbf{1 a}$ (red isomer-1) and $\mathbf{1 b}$ (white isomer-2)}

The details of the crystal and experimental data for compounds $\mathbf{1 a}$ and $\mathbf{1 b}$ are listed in table 1. Selected bond distances and bond angles are given in Supplementary Information, table S1. The data presented in table S1 show that the bond lengths of the selected atoms fall in their respective single or double bond range. The molecular structures of the compounds 1a and $\mathbf{1 b}$ are shown in figures 1 and 2, respectively. Packing and hydrogen bonding interactions are illustrated in Supplementary Information, figures S2-S5. The packing diagram of the compound 1a (red isomer) makes a wave like structure when viewed along a-axis as shown in figure $\mathrm{S} 2$. The same molecule when viewed along c-axis, then it forms a sandwitch like structure as given in figure S3. The packing diagram of the compound $\mathbf{1 b}$ (white isomer) makes a zig-zag-like structure

Table 1. Crystal data and refinement parameters of $\mathbf{1 a}$ (red isomer) and $\mathbf{1 b}$ (white isomer).

\begin{tabular}{|c|c|c|}
\hline & $\begin{array}{c}1 \mathbf{a} \text { (red isomer) } \\
\text { CCDC No. } 984384\end{array}$ & $\begin{array}{l}\text { 1b (white isomer) } \\
\text { CCDC No. } 984383\end{array}$ \\
\hline Chemical formula & $\mathrm{C}_{16} \mathrm{H}_{14} \mathrm{~N}_{4} \mathrm{O}_{4}$ & $\mathrm{C}_{16} \mathrm{H}_{14} \mathrm{~N}_{4} \mathrm{O}_{4}$ \\
\hline$M_{\mathrm{r}}$ & 326.31 & 326.31 \\
\hline Crystal system, space group & Orthorhombic, pbcn & Triclinic, $P^{-1}$ \\
\hline Temperature $(\mathrm{K})$ & 130 & 140 \\
\hline$a, b, c(\AA)$ & $\begin{array}{c}12.7612(4), 11.5197(3) \\
20.1586(7)\end{array}$ & $\begin{array}{c}7.8007(4), 8.5966(7) \\
12.224(1)\end{array}$ \\
\hline$\alpha, \beta, \gamma\left(^{\circ}\right)$ & $90,90,90$ & $\begin{array}{c}71.133(7), 81.281(5) \\
74.895(5)\end{array}$ \\
\hline$V\left(\AA^{3}\right)$ & $2963.42(16)$ & $746.86(9)$ \\
\hline$Z$ & 8 & 2 \\
\hline$F(000)$ & 1360 & 340 \\
\hline$D_{x}\left(\mathrm{Mg} \mathrm{m}^{-3}\right)$ & 1.463 & 1.451 \\
\hline Radiation type & Mo $K \alpha$ & Mo $K \alpha$ \\
\hline $\begin{array}{l}\text { No. of reflections for cell } \\
\text { measurement }\end{array}$ & 14528 & 3242 \\
\hline$\theta$ range $\left(^{\circ}\right)$ for cell measurement & $3.1-27.5$ & $3.1-27.5$ \\
\hline$\mu\left(\mathrm{mm}^{-1}\right)$ & 0.11 & 0.11 \\
\hline Crystal shape & Prism & Prism \\
\hline Colour & Red & Colourless \\
\hline Crystal size (mm) & $0.25 \times 0.19 \times 0.10$ & $0.22 \times 0.17 \times 0.15$ \\
\hline $\begin{array}{l}\text { No. of measured, independent } \\
\text { and observed }[I>2 \sigma(I)] \text { reflections }\end{array}$ & $21937,3228,2452$ & $5541,3249,2393$ \\
\hline$R_{\text {int }}$ & 0.037 & 0.024 \\
\hline$\theta$ values $\left(^{\circ}\right)$ & $\theta_{\max }=27.0, \theta_{\min }=3.1$ & $\theta_{\max }=27.0, \theta_{\min }=3.1$ \\
\hline$(\sin \theta / \lambda)_{\max }\left(\AA^{-1}\right)$ & 0.639 & 0.639 \\
\hline Range of $h, k, l$ & $\begin{array}{c}h=-15 \rightarrow 16, k=-14 \rightarrow 14, \\
l=-20 \rightarrow 25\end{array}$ & $\begin{array}{c}h=-9 \rightarrow 9, k=-10 \rightarrow 10, \\
l=-15 \rightarrow 14\end{array}$ \\
\hline Refinement on & $F^{2}$ & $F^{2}$ \\
\hline$R\left[F^{2}>2 \sigma\left(F^{2}\right)\right], w R\left(F^{2}\right), S$ & $0.037,0.108,1.03$ & $0.045,0.120,1.04$ \\
\hline No. of reflections & 3228 & 3249 \\
\hline No. of parameters & 219 & 219 \\
\hline No. of restraints & 0 & 0 \\
\hline H-atom treatment & H-atom parameters constrained & $\mathrm{H}$-atom parameters constrained \\
\hline Weighting scheme & $\begin{array}{c}w=1 /\left[\sigma^{2}\left(F_{\mathrm{o}}^{2}\right)+(0.0579 P)^{2}\right. \\
+0.3184 P]\end{array}$ & $\begin{array}{c}w=1 /\left[\sigma^{2}\left(F_{\mathrm{o}}^{2}\right)+(0.0485 P)^{2}\right. \\
+0.078 P]\end{array}$ \\
\hline$(\Delta / \sigma)_{\max }$ & where $\begin{aligned} P & =\left(F_{\mathrm{o}}^{2}+2 F_{\mathrm{c}}^{2}\right) / 3 \\
& <0.0001\end{aligned}$ & where $\begin{aligned} P & =\left(F_{\mathrm{o}}^{2}+2 F_{\mathrm{c}}^{2}\right) / 3 \\
& <0.0001\end{aligned}$ \\
\hline$\Delta \rho_{\max }, \Delta \rho_{\min }\left(\mathrm{e} \AA^{-3}\right)$ & $0.22,-0.21$ & $0.21,-0.25$ \\
\hline CCDC & 984384 & 984383 \\
\hline
\end{tabular}




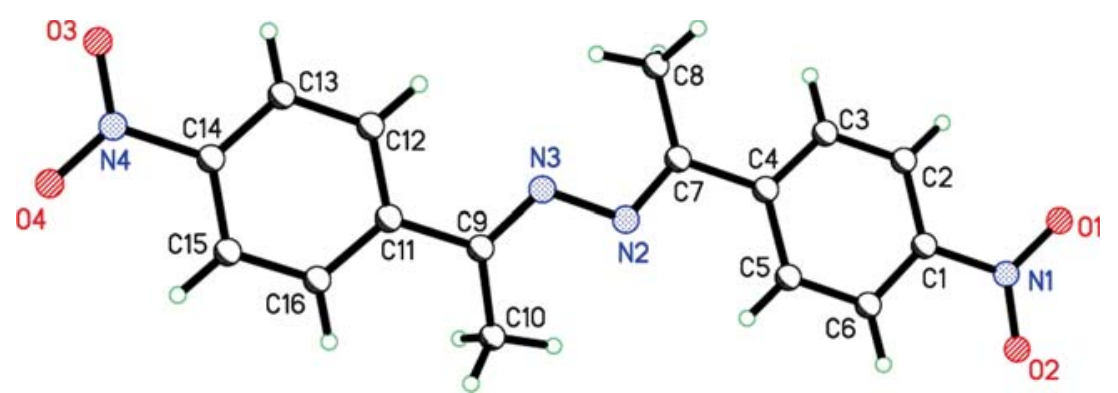

Figure 1. ORTEP view of compound 1a (red isomer) with the atomic numbering scheme. Displacement ellipsoids for non-H atoms are drawn at the $50 \%$ probability level.

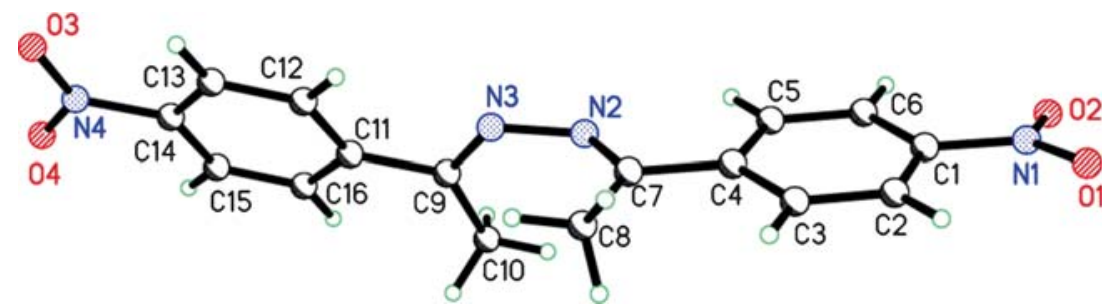

Figure 2. ORTEP view of compound $\mathbf{1 b}$ (white isomer) with the atomic numbering scheme. Displacement ellipsoids for non-H atoms are drawn at the $50 \%$ probability level.

as shown in figure $\mathrm{S} 4$ when viewed along b-axis and a wall- like structure along c-axis (figure S5). Hydrogen bond parameters for compounds $\mathbf{1 a}$ and $\mathbf{1 b}$ are given in table $\mathrm{S} 2$. It can be seen from table $\mathrm{S} 2$, that there are three types of $\mathrm{H}$-bondings in compound 1a (red isomer): C8-H8A...N3 = 2.7495(18) $\AA$; $\mathrm{C} 10-\mathrm{H} 10 \mathrm{~A} \ldots \mathrm{N} 2=2.7403(18) \AA ; \mathrm{C} 13-\mathrm{H} 13 \ldots \mathrm{O} 1$ $=3.3255(17) \AA$ while in compound $\mathbf{1 b}$ (white isomer) there are five types: $\mathrm{C} 2-\mathrm{H} 2 \ldots \mathrm{O} 3=3.451(2) \AA$; $\mathrm{C} 5-$ $\mathrm{H} 5 . . \mathrm{O} 4=3.180(2) \AA ;$ C8-H8A...N3 = 2.798(3) $\mathrm{A}$; $\mathrm{C} 10-\mathrm{H} 10 \mathrm{~A} \ldots \mathrm{N} 2=2.791(2) \AA{ }^{\circ} ; \mathrm{C} 12-\mathrm{H} 12 \ldots \mathrm{O} 2=$ 3.324(2) A.

The single crystal X-ray analysis reveals that the title hydrazine derivatives 1a (red isomer) and 1b (white isomer) crystallize respectively as orthorhombic crystal system with space group $P b c n$ and triclinic crystal system with space group $P^{-1}$ (See Supplementary Information). The structure of compound 1a has been reported by Glaser et al..$^{23}$ at room temperature $(295 \mathrm{~K})$. But we have determined the crystal structure of 1a at low temperature (130 (2) K) and confirm here its thermo-isomerism for the first time. Molecules of both compounds (1a and $\mathbf{1 b}$ ) are twisted at N2-N3 bond with the C7-N2-N3-C9 torsion angle of $155.23(12)^{\circ}$ and $-113.36(18)^{\circ}$, respectively. The dihedral angles between the two aromatic rings are $16.51(6)^{\circ}$ for $\mathbf{1 a}$ and $62.11(8)^{\circ}$ for $\mathbf{1 b}$. All bond lengths and bond angles in $\mathbf{1 a}$ and $\mathbf{1 b}$ are normal and agree well with that previously reported for similar structure ${ }^{23}$ and with each other. In the crystal structure of both isomers (1a and 1b), molecular conformations are stabilized by weak intramolecular $\mathrm{C}-\mathrm{H}$. . . N contacts. Intermolecular $\mathrm{O}-\mathrm{O}$ interactions $(2.914 \AA)$ of the nitro groups stabilize the crystal structure (figure 3). Furthermore, $\pi-\pi$ stacking interactions [centroid-centroid distances $=3.5717(7)$ and 3.5599(7) $\AA$ for 1a, and 3.8656(10) and 3.6255(10) $\AA$ for $\mathbf{1 b}$ ] exist between the same aromatic rings of molecules.

\subsection{Thermo-isomerism of red isomer (1a) to white isomer $(\mathbf{1 b})$}

The cisoid-transoid isomerism chemical equilibrium is highly aromatically driven to the formation of two stabilized isomers. Cisoid-transoid isomerism is important in several areas of biochemistry and physics applications; rare trans diazine isomers can lead to cis mutation because of their altered base-pairing properties. In the present case, the trans form is greatly favored due to aromatic stabilization and minimum steric repulsion. The system in transoid form is fully conjugated. The trans-cis interconversion rate $(85 / 15)$ under reflux of $\mathrm{MeOH}$ is not completed definitively. It was determined accidently by comparison of the amount of $\mathbf{1 b}$ as a co-product of $\mathbf{1 a}$ and using crystallographic analyses. 


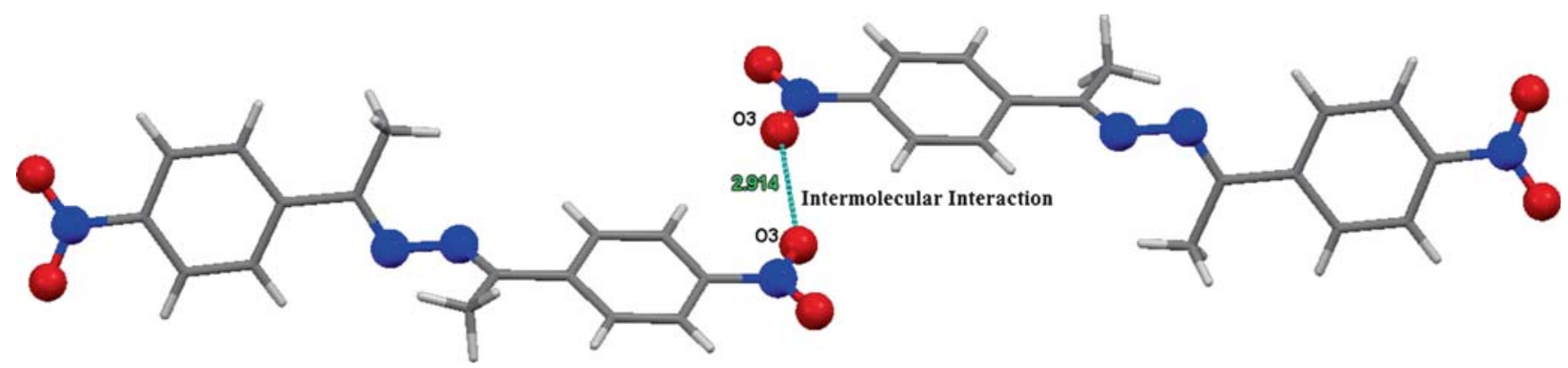

Figure 3. View of intermolecular interaction in $\mathbf{1 b}$ (white isomer).

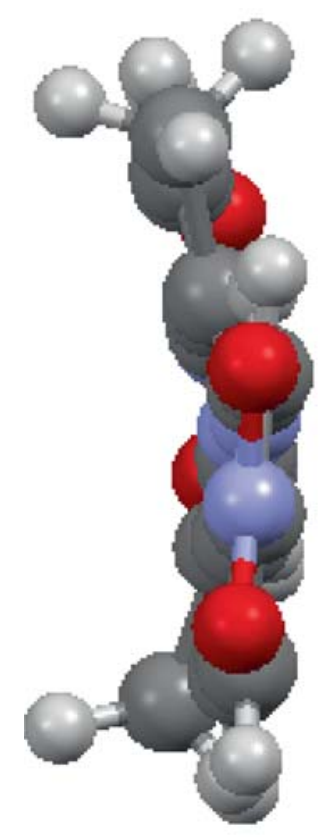

(a) (red Isomer-1)

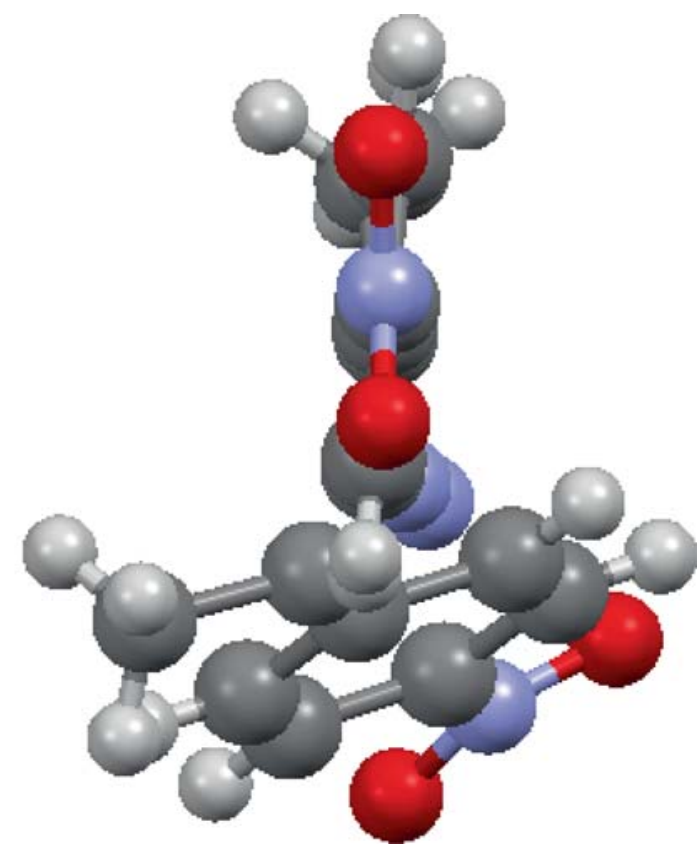

(b) (white Isomer-2)

Figure 4. Origin of switch of colors: from planar (red) to non-planar (white) structure.

The geometry of $\mathbf{1 a}$ is semi-flexible because of the presence of N-N semi-pi-conjugated bond of $\mathrm{C}=\mathrm{N}$ $\mathrm{N}=\mathrm{C}$ as central moiety, the molecule is planar and the favored geometry is that which presents less hindered/steric obstruction (figure 4). This compound can act as a colored (red isomer 1a) or colorless dye (white isomer 1b) when heating in alcohols.

\section{Conclusions}

Hydrazone undergoes trans-cis isomerism when heated in an appropriate solvent. The reverse trans-cis thermoisomerism can be driven also by light or occurs thermally in the dark. Thermochromatic properties of hydrazones make it an ideal component of numerous molecular devices and functional materials. Despite the abundance of application-driven research, hydrazone, azobenzene photochemistry and the isomerization mechanisms remain topics of investigation. Understanding the differences in thermo and photochemistry, which originates from substitution, is imperative in exploiting hydrazone and azobenzene in desired applications.

\section{Supplementary Information}

Supplementary information is available at www.ias.ac. in/chemsci.

\section{Acknowledgements}

The authors would like to extend their sincere appreciation to the Deanship of Scientific Research at King Saud University for its funding this Research group No. (RG -007-2016). 


\section{References}

1. Asik S I J, Fun H K, Razak I A, Jansrisewangwong P and Chantraproma S 2012 Acta Cryst. E68 o643

2. Archana R, Anbazhagan R, Sankaran K R, Thiruvalluvar A and Butcher R J 2010 Acta Cryst. E66 o1586

3. Bandara H M D and Burdette S C 2012 Chem. Soc. Rev. 411809

4. Chang J G, He G F and Li Y F 2007 Acta Cryst. E63 o3982

5. Chang J G, Zhao D F, He G F and Li J K 2007 Acta Cryst. E63 03297

6. Chang J G and Li J K 2007 Acta Cryst. E63 o4061

7. Chang J G and Liu X H 2007 Acta Cryst. E63 03382

8. Chang J G 2009 Acta Cryst. E65 o2767

9. Glaser R, Murphy R F, Sui Y, Barnes C L and Kim S H 2006 Cryst. Eng. Comm. 8372

10. Glaser R, Knotts N, Yu P, Li L, Chandrasekhar M, Martin C and Barnes C L 2006 Dalton Trans. 2891

11. Lewis M, Barnes C L, Hathaway B A and Glaser R 1999 Acta Cryst. C55 975
12. Lewis M, Barnes C L and Glaser R 2000 Acta Cryst. C56 393

13. Qu Y 2005 Sun and X M Acta Cryst. E61 o3828

14. Safari J and Gandomi-Ravandi S 2014 RSC Adv. 4 46224

15. Sauro V A and Workentin M S $2001 \mathrm{~J}$. Org. Chem. 66 831

16. Wallace K J, Morey J, Lynch V M and Anslyn E V 2005 New J. Chem. 291469

17. Wang Q H, Guo G C and Wang M S 2005 Acta Cryst. E61 o1156

18. Bruker (2005) APEX2 (version 2.1) and SAINT (version 7.23A). Bruker AXS Inc., Madison, USA

19. Altomare A, Burla M C, Camalli M, Cascarano G L, Giacovazzo C, Guagliardi A, Moliterni A G G, Polidori G and Spagna R 1999 J. Appl. Cryst. 32 115

20. Sheldrick G M 2008 Acta. Cryst. A64 112

21. Farrugia L J 1997 J. Appl. Cryst. 30565

22. Farrugia L J 1999 J. Appl. Cryst. 32837

23. Glaser R, Chen G S, Anthamatten M and Barnes C L 1995 J. Chem. Soc. Perkin Trans. 2144 